\title{
In vitro vasoactive effects of dexmedetomidine on isolated human umbilical arteries
}

\author{
Arun $\mathrm{O}^{1}$, Taylan $\mathrm{SB}^{2}$, Duman $\mathrm{I}^{3}$, Oc B $\mathrm{B}^{1}$, Yilmaz $\mathrm{SA}^{4}$, Tekin $\mathrm{A}^{4}$, Celik $\mathrm{C}^{4}$, Bariskaner $\mathrm{H}^{2}$, Celik $\mathrm{JB}^{1}$ \\ Department of Anesthesiology and Reanimation, Selcuk University, Faculty of Medicine, Konya, Turkey. \\ oguzarun@selcuk.edu.tr
}

\begin{abstract}
OBJECTIVE: We aimed to investigate the vasoactive effects of dexmedetomidine on isolated human umbilical arteries and possible mechanisms involved.

METHODS: Human umbilical artery strips were suspended in Krebs-Henseleit solution and dose-response curves were obtained for cumulative dexmedetomidine before and after incubation with different agents; propranolol, atropine, yohimbine, prazosin, indomethacin, verapamil. Effects of calcium on cumulative dexmedetomidineinduced contractions were also studied.

RESULTS: Cumulative dexmedetomidine resulted in dose dependent contraction responses. Incubation with propranolol (Emax: $93.3 \pm 3.26 \%$ ), atropine (Emax: $92.0 \pm 6.54 \%$ ), or indomethacin (Emax: $94.25 \pm 2.62 \%$ ), did not attenuate dexmedetomidine-elicited contractions $(p>0.05)$. There were significant decreases in the contraction responses of cumulative dexmedetomidine with_yohimbine (Emax: $12.1 \pm 11.9 \%$ ), prazosin (Emax: $28.8 \pm 4.6 \%$ ) and verapamil (Emax: $11.2 \pm 13.6 \%)(p<0.05)$. In $\mathrm{Ca}^{+2}$ free medium contraction responses to cumulative dexmedetomidine was insignificant (Emax: $5.20 \pm 3.42 \%$ ). Addition of cumulative calcium to the $\mathrm{Ca}^{+2}$ free medium resulted in concentration dependent increase in contractions (Emax: $64.83 \pm 37.7 \%)(p<0.05)$. CONCLUSION: Dexmedetomidine induces vasoconstriction in endothelial-free umbilical arteries via both, $\alpha_{1}-$ and $\alpha_{2}$-adrenergic receptors and also extracellular $\mathrm{Ca}^{+2}$ concentrations play a major role. $\beta$-adrenergic receptors, muscarinic cholinergic receptors, and inhibition of cyclooxygenase enzyme are not involved in this vasoconstriction (Fig. 3, Ref. 36). Text in PDF www.elis.sk.

KEY WORDS: alpha adrenergic receptors, dexmedetomidine, in vitro, umbilical cord, vascular smooth muscle.
\end{abstract}

\section{Introduction}

Dexmedetomidine, an $\alpha_{2}$-adrenergic receptor agonist, has been used for sedation and analgesia and as an adjunct to anesthesia because of its sedative, analgesic and sympatholytic properties (1). The $\alpha_{2}: \alpha_{1}$ adrenoreceptor specificity ratio of dexmedetomidine is ten times than clonidine $(1,600: 1)(2)$. This $\alpha_{2}$ specificity and a short half-life of six minutes make dexmedetomidine ideal for intravenous titration for sedation and anxiolysis. The Food and Drug Administration (FDA) has approved dexmedetomidine for limited use for sedation, mechanical ventilation and monitored anesthesia care in adults (3). There are current reports on the intraoperative use of dexmedetomidine for various indications including Cesarean sections (4-8). It is crucial to elucidate the possible effects of dexmedetomidine on the uterus and fetal circulation.

${ }^{1}$ Department of Anesthesiology and Reanimation, Selcuk University, Faculty of Medicine, Konya, Turkey, ${ }^{2}$ Department of Pharmacology, Selcuk University, Faculty of Medicine, Konya, Turkey, ${ }^{3}$ Department of Medical Pharmacology, Necmettin Erbakan University, Meram Faculty of Medicine, Konya, Turkey, and ${ }^{4}$ Department of Gynecology and Obstetrics, Selcuk University, Faculty of Medicine, Konya, Turkey

Address for correspondence: O. Arun, MD, Selcuk University Faculty of Medicine Department of Anesthesiology and Reanimation, Alaeddin Keykubad Yerleskesi Yeni Istanbul Street No. 313, Selcuklu Konya 42130. Phone: +90.532.6686993, Fax: +90.332.2245178
Dexmedetomidine increases uterine contractility (9) and is transported into the fetal circulation in small amounts (10). Except for the segment that is closest to the fetus, the umbilical cord and the placenta do not contain nerve fibers and are not innervated. The umbilical blood flow mainly depends on local vasoconstrictors such as endothelin-1 and thromboxane and also vasodilators such as prostacyclin $\left(\mathrm{PGI}_{2}\right)$ and nitric oxide $(\mathrm{NO})(11,12)$. The direct effects of vasoactive agents on umbilical vessels are essential due to lack of autonomic innervations (13).

There is no information on the direct effects of dexmedetomidine on human umbilical vessels. This in vitro study was designed to investigate the vasoactive effects of dexmedetomidine on isolated human umbilical arteries and possible mechanisms involved.

\section{Materials and methods}

The Institutional Human Ethics Committee approved this study. The umbilical cords were remnant tissues which would have otherwise been discarded.

\section{Collection of samples}

After written maternal consent, human umbilical cords were collected from full-term healthy normal vaginal deliveries. After delivery, the umbilical cord was clamped at both placental and fetal ends. An untouched $10-15 \mathrm{~cm}$ long segment of the cord from the 


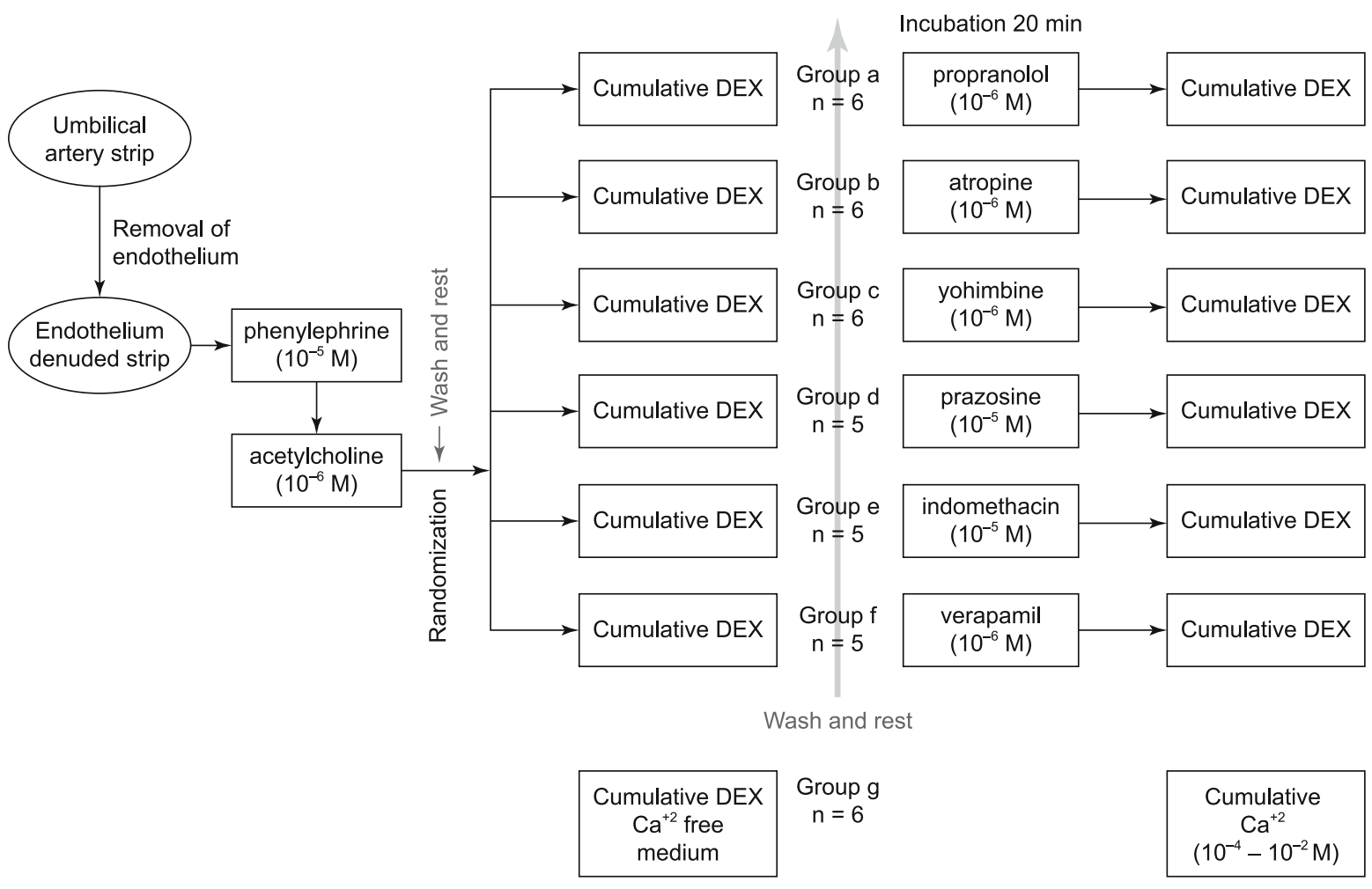

Fig. 1. Flow chart of experimental procedures. DEX: dexmedetomidine $\left(10^{-9}-2 \times 10^{-5} \mathrm{M}\right)$

placental end was removed within 10 min of delivery and placed in cold Krebs-Henseleit $(\mathrm{KH})$ solution for immediate transport to the laboratory.

\section{Blood vessel preparation}

Umbilical arteries were separated from the surrounding tissue in $\mathrm{KH}$ solution. The isolated artery was cut spirally to form 2-3 $\mathrm{mm}$ wide and $15-20 \mathrm{~mm}$ long strips. The strips were transferred to organ baths containing $20 \mathrm{ml}$ of $\mathrm{KH}$ solution maintained at $37^{\circ} \mathrm{C}$. Then the strips were suspended between two hooks; one anchored onto the organ bath and the other connected to a transducer. Smooth muscle contractions were recorded with a forcedisplacement transducer and digitized data acquisition system (MP35, BIOPAC, Goleta, CA, USA). Strips were aerated with a gas mixture of $95 \% \mathrm{O}_{2}: 5 \% \mathrm{CO}_{2}$ throughout the experiment. Strips were initially placed under a resting tension of $1 \mathrm{~g}$ and were allowed to equilibrate for one hour. During this period the bath solution was changed every 15 minutes, and the resting tension was readjusted to the $1 \mathrm{~g}$ level.

\section{Experimental protocol}

Experimental procedures are summarized in Figure 1. Human umbilical artery strips without endothelium were used during the experiment. Endothelium removal was done by gently denuding the endothelium with cotton swabs. Following the washout period endothelium removal of the strips was examined by contracting the strips with phenylephrine $\left(10^{-5} \mathrm{M}\right)$ and testing with acetylcholine $\left(10^{-6} \mathrm{M}\right)$. Strips free of endothelium did not relax with acetylcholine. The strips were rewashed with the buffer solution and allowed to rest. Strips were randomly allocated to study groups.

To assess the possible mechanisms of dexmedetomidine's vascular effects, first, the reactivity of the human umbilical artery to dexmedetomidine was examined. The strips at resting tension in each study group (a to $g)(n=6$ or $n=5)$ were subjected to cumulative concentrations of dexmedetomidine $\left(10^{-9}-2 \times 10^{-5}\right.$ $\mathrm{M})$, and dose-response curves were recorded. After washing and allowing the strips to rest for one hour, response curves of cumulative dexmedetomidine $\left(10^{-9}-2 \times 10^{-5} \mathrm{M}\right)$ were obtained in these groups after the strips were incubated for $20 \mathrm{~min}$ with different agents; a) propranolol $\left(10^{-6} \mathrm{M}\right)(\mathrm{n}=6)$ a non-selective $\beta$-adrenergic antagonist, b) atropine $\left(10^{-6} \mathrm{M}\right)(\mathrm{n}=6)$ a competitive antagonist of muscarinic cholinergic receptors, $\mathrm{c})$ yohimbine $\left(10^{-6} \mathrm{M}\right)(\mathrm{n}=6)$ an $\alpha_{2}$-adrenergic antagonist, d) prazosin $\left(10^{-5} \mathrm{M}\right)$ $(\mathrm{n}=5)$ an $\alpha_{1}$-adrenergic antagonist, e) indomethacin $\left(10^{-5} \mathrm{M}\right)(\mathrm{n}$ $=5)$ a cyclooxygenase enzyme inhibitor, f) verapamil $\left(10^{-6} \mathrm{M}\right)$ $(\mathrm{n}=5)$ a L-type voltage-sensitive $\mathrm{Ca}^{2+}$ channel blocker, and g) in $\mathrm{Ca}^{+2}$ free modified $\mathrm{KH}$ solution $(\mathrm{n}=6)$. The effect of $\mathrm{Ca}^{+2}$ was assessed by first recording $2 \times 10^{-5} \mathrm{M}$ dexmedetomidine-induced control contraction in $\mathrm{KH}$ solution. The strips were washed and allowed to rest in $\mathrm{Ca}^{+2}$ free $\mathrm{KH}$ solution for one hour. At the end of the resting period, dose-response curves of cumulative dexmedetomidine $\left(10^{-9}-2 \times 10^{-5} \mathrm{M}\right)$ in $\mathrm{Ca}^{+2}$ free medium were recorded. 

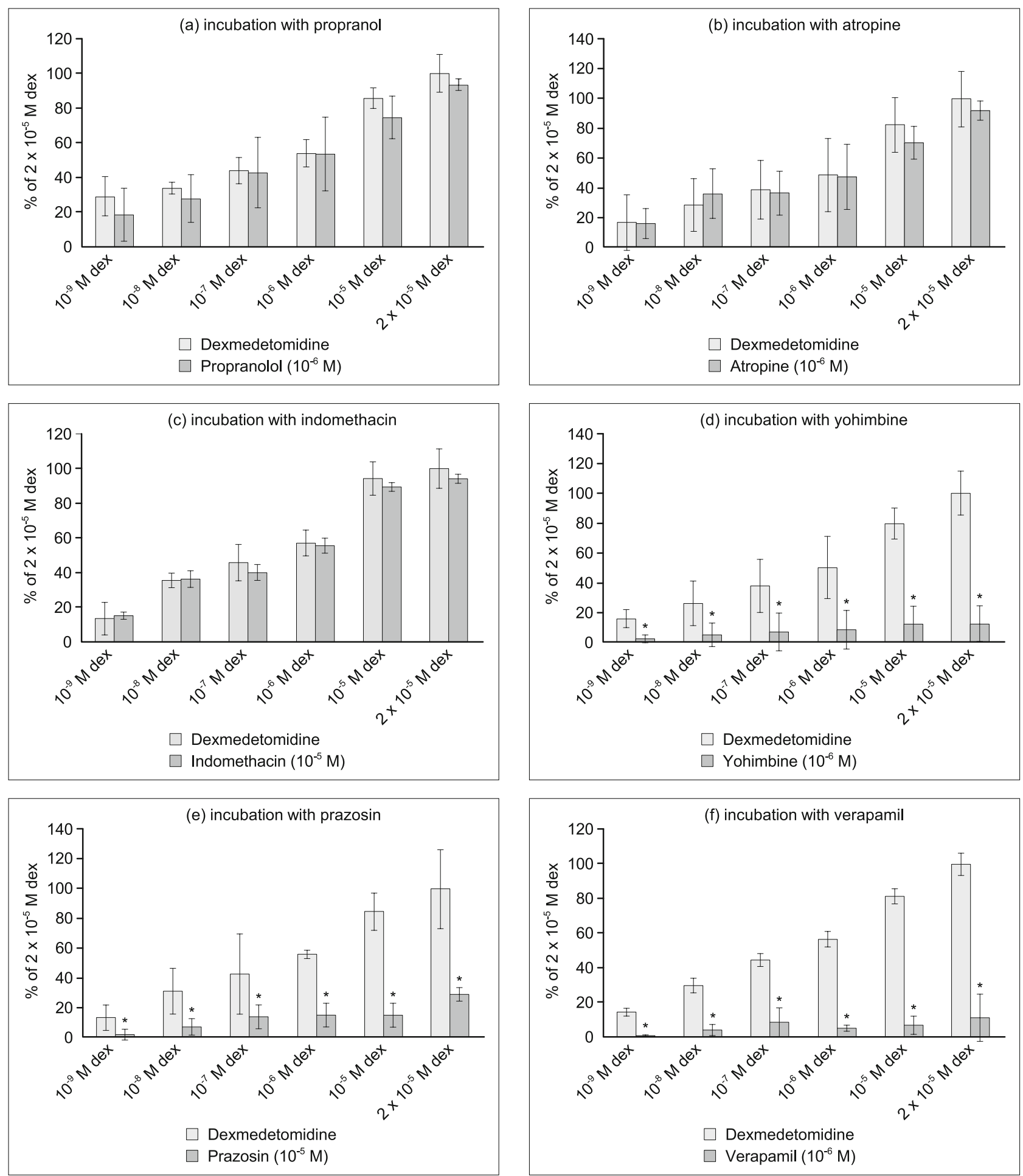

Fig. 2. Effects of incubation with different agents on cumulative dexmedetomidine induced contractions in human umbilical arteries. Groups: propranolol (a), atropine (b), yohimbine (c), prazosin (d), indomethacin (e) or verapamil (f). Results are \% of $2 \times 10^{-5} \mathrm{M}$ dexmedetomidine induced maximum contraction (mean $\pm \mathrm{SD}$ ), dex: dexmedetomidine, ${ }^{*} \mathbf{p}<\mathbf{0 . 0 5}$ compared to same concentration of dexmedetomidine.

After recording the contraction to the maximum concentration of dexmedetomidine $\left(2 \times 10^{-5} \mathrm{M}\right)$ in $\mathrm{Ca}^{+2}$ free medium, contraction responses were obtained by adding cumulative $\mathrm{Ca}^{+2}\left(10^{-4}-10^{-2}\right.$ $\mathrm{M})$ into the media.
Each strip was used for only one experiment. Results are given as $\%$ of maximum contraction induced by $2 \times 10^{-5} \mathrm{M}$ dexmedetomidine in each group. Wilcoxon rank test was used for analysis, a p-value less than 0.05 was considered as significant. 

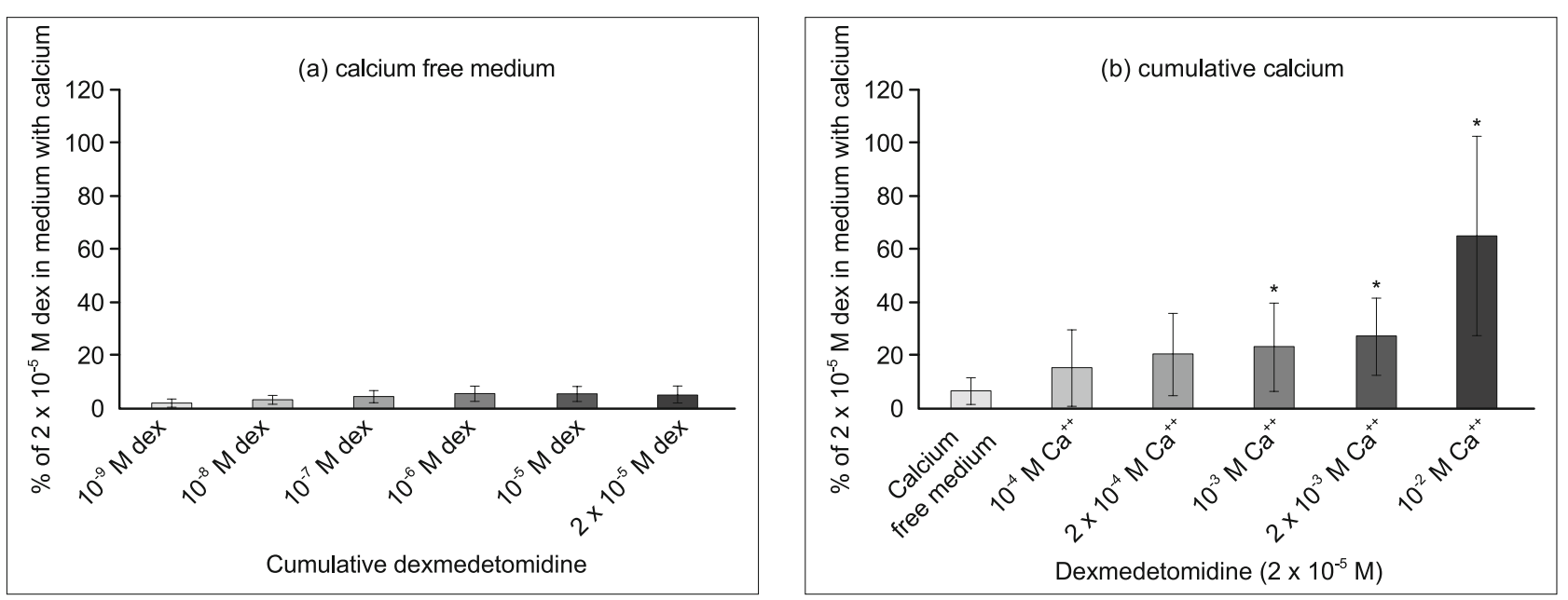

Fig. 3. Effects of calcium on dexmedetomidine induced contractions in human umbilical arteries. a) cumulative dexmedetomidine in calcium free medium, b) cumulative calcium on maximum dexmedetomidine contraction. Results are $\%$ of $2 \times 10^{-5} \mathrm{M}$ dexmedetomidine induced control contraction (mean \pm SD), dex: dexmedetomidine, ${ }^{*} \mathbf{p}<0.05$ compared to calcium free medium.

\section{Materials}

Modified Krebs-Henseleit solution and modified KrebsHenseleit without $\mathrm{Ca}^{+2}$ were prepared in the laboratory with compositions of (in $\mathrm{mM}$ ) $\mathrm{NaCl} 119 ; \mathrm{KCl} 4.7 ; \mathrm{MgSO}_{4} 1.5 ; \mathrm{KH}_{2} \mathrm{PO}_{4} 1.2$; $\mathrm{CaCl}_{2} 2.5 ; \mathrm{NaHCO}_{3} 25$; glucose 11 , and $\mathrm{NaCl} 119 ; \mathrm{KCl} 4.7 ; \mathrm{MgSO}_{4}$ 1.5; $\mathrm{KH}_{2} \mathrm{PO}_{4} 1.2 ; \mathrm{NaHCO}_{3} 25$; glucose 11, EGTA 1 respectively. Dexmedetomidine was obtained from Koçak Farma (Istanbul, Turkey). All other drugs (atropine, acetylcholine, phenylephrine, indomethacin, prazosin, propranolol, verapamil, and yohimbine), were obtained from Sigma-Aldrich (St. Louis, MO, USA). The drugs were prepared and subsequently diluted in distilled water. All concentrations are expressed as final molar concentrations (M).

\section{Results}

Cumulative dexmedetomidine resulted in dose dependent contraction responses in umbilical artery strips. Incubation with propranolol (Emax: $93.3 \pm 3.26 \%$ ), atropine (Emax: $92.0 \pm 6.54 \%$ ), or indomethacin (Emax: $94.25 \pm 2.62 \%$ ), did not significantly attenuate dexmedetomidine-elicited contractions (Figs 2a, b, c) (p $>0.05)$. There were statistically significant decreases in the contraction responses of cumulative dexmedetomidine in the presence of yohimbine (Emax: $12.1 \pm 11.9 \%$ ) (Fig. 2d), prazosin (Emax: $28.8 \pm 4.6 \%$ ) (Fig. $2 \mathrm{e}$ ) and verapamil (Emax: $11.2 \pm 13.6 \%$ ) (Fig. 2f) $(\mathrm{p}<0.05)$.

In $\mathrm{Ca}^{+2}$ free medium the contraction responses to cumulative dexmedetomidine were insignificant (Emax: $5.20 \pm 3.42 \%$ ) (Fig. $3 a)$. Addition of cumulative calcium to the $\mathrm{Ca}^{+2}$ free medium resulted in concentration dependent increase in the dexmedetomidine induced contractions (Emax: $64.83 \pm 37.7 \%$ ) (Fig. 3b) $(\mathrm{p}<0.05)$.

\section{Discussion}

The present in vitro study shows that in endothelium free umbilical arteries, dexmedetomidine causes dose-dependent va- soconstriction. Our results also demonstrate that dexmedetomidine leads to vasoconstriction in endothelium-denuded umbilical artery strips via both the $\alpha_{1}$ and $\alpha_{2}$-adrenergic receptors at both low and high concentrations. These results are in part different from previous research which reported that through postsynaptic $\alpha_{2}$-receptor activation, dexmedetomidine causes vasoconstriction in various human and animal vessels, including coronary arteries, peripheral arterioles, cerebral arteries, gastroepiploic and brachial arteries (14-17). According to some of these studies, $\alpha 1$-adrenergic receptors contribute to vasoconstriction at high concentrations of dexmedetomidine $(15,17)$. In a study showing the vasoconstrictor effect of dexmedetomidine on human internal mammary artery (IMA), yohimbine attenuated the contraction resulting from lower doses of dexmedetomidine, whereas prazosin attenuated contraction resulting at higher doses of dexmedetomidine. Their data suggest that dexmedetomidine causes contraction by activating $\alpha_{2}$-adrenergic receptors at lower concentrations, but it may also activate $\alpha_{1}$-adrenergic receptors at higher concentrations in IMA (15). It is suggested that the contractile adrenergic receptors in the human umbilical artery consist of both $\alpha_{1}$ and $\alpha_{2}$ subtypes (18). In the present study $\alpha_{1}$ - adrenergic receptor antagonist prazosin significantly inhibited the constriction at both low and high concentrations of dexmedetomidine; suggesting that both $\alpha_{1}$-receptors, as well as $\alpha_{2}$-receptors, are involved in the vasoconstrictor effect of dexmedetomidine on the umbilical artery.

The present study was conducted on endothelium denuded vascular rings, which provides us to study the direct effects of drugs on vascular smooth muscle by removing endothelial factors. In vivo, $\alpha_{2}$-adrenergic agonists can have different results. They may diminish norepinephrine release by prejunctional $\alpha_{2}$-adrenergic receptor stimulation, thereby decreasing local and circulating catecholamines $(19,20)$ or may activate $\alpha_{2}$-adrenergic receptors on endothelial cells, resulting in the release of endothelium-derived NO (14).

Vasoconstriction is controlled by calcium-dependent and calcium sensitization mechanisms (21). Calcium influx from the ex- 
tracellular space and release from the sarcoplasmic reticulum are associated with intracellular free $\mathrm{Ca}^{2+}$ concentrations. Dexmedetomidine-induced vasoconstriction involves calcium sensitization mediated by Rho kinase, protein kinase $\mathrm{C}$, and phosphoinositide 3-kinase (22)._In the present study, verapamil and $\mathrm{Ca}^{2+}$ free medium resulted in minor contractions. Incubation with verapamil and $\mathrm{Ca}^{2+}$ free medium significantly decreased but did not block these contractions suggesting; significant involvement of extracellular $\mathrm{Ca}^{2+}$ rather than release from intracellular $\mathrm{Ca}^{2+}$ stores. Some of the effects of postsynaptic $\alpha_{2}$-adrenergic receptors on vascular smooth muscle cells are mediated by molecular mechanisms that are common to $\alpha_{2}$ and $\alpha_{1}$ adrenergic receptors (23). Different G protein signal transduction pathways mediate the primary coupling mechanisms of $\alpha 1$ and $\alpha 2$ adrenergic receptors. $\alpha_{1}$ adrenergic receptors signal through Gq-proteins (24), activate smooth muscle contraction through the phospholipase $\mathrm{C}$ - inositol trisphosphate $\left(\mathrm{IP}_{3}\right)$ signal transduction pathway (25). In addition to mobilizing intracellular calcium, depending on the receptor subtype of the vessel, the $\alpha_{1}$-adrenergic receptors have also been shown to activate calcium influx via L-type voltage-sensitive $\mathrm{Ca}^{2+}$ channels $(26,27$, 28 ), whereas $\alpha_{2}$ adrenergic receptors signal via Gi proteins that inhibit adenylyl cyclase activity and decrease intracellular cAMP in smooth muscle cells but may also mediate stimulation extracellular $\mathrm{Ca}^{2+}$ influx through voltage-sensitive $\mathrm{Ca}^{2+}$ channels $(23,29,30)$.

Potentially useful features of dexmedetomidine have expanded the off-label use of the drug outside of the ICU, including adjunctive for spinal and epidural anesthesia for Cesarean section (5-7), sedation for eclampsia (31), anxiolysis during laboring or Cesarean section $(32,33)$. Potential advantages of $\alpha_{2}$-agonists during obstetric practice bring the need to further assess the pharmacological effects and safety of dexmedetomidine on the uterus, placenta and the umbilical circulation. Dexmedetomidine enhances spontaneous contractions in-vitro in rat and human myometrium $(8,34)$. Due to its high lipophilicity dexmedetomidine crosses the placenta less readily than clonidine but still should be used during pregnancy only if the benefits justify the risk to the fetus $(10,35)$.

This study has several limitations. It is an in vitro study. The clinical effects of dexmedetomidine on umbilical vessels may be different from our in-vitro results. It was conducted on endothelium denuded vasculature aiming to study the direct effects of drugs on vascular smooth muscle. Our results were not affected by the vasoactive substances of the endothelium such as NO. Dexmedetomidine possesses an imidazoline ring in its structure, and vascular $\mathrm{K}_{\mathrm{ATP}}$-channel inhibition may be an underlying mechanism of the vasoconstriction (36). The present study did not assess the $\mathrm{K}^{+}$channel activity.

\section{Conclusion}

Different from other vasculature, dexmedetomidine has a concentration-dependent vasoconstrictive effect on the endothelial-free umbilical artery via both $\alpha_{1}$ - and $\alpha_{2}$-adrenergic receptors. Dexmedetomidine-induced vasoconstriction is dependent on extracellular $\mathrm{Ca}^{2+}$ concentrations and calcium influx via Ltype voltage-sensitive $\mathrm{Ca}^{2+}$ channels. Also $\beta$-adrenergic receptors, muscarinic cholinergic receptors and inhibition of cyclooxygenase enzyme are not involved in direct mechanisms regulating the effects of dexmedetomidine on smooth muscle vascular tone of the umbilical artery.

\section{References}

1. Sottas CE, Anderson BJ. Dexmedetomidine: the new all-in-one drug in paediatric anaesthesia? Curr Opin Anaesthesiol 2017; 30 (4): $441-451$.

2. Buck ML. Dexmedetomidine use in pediatric intensive care and procedural sedation. J Pediatr Pharmacol Ther 2010; 15 (1): 17-29.

3. Kamibayashi T, Maze M. Clinical uses of alpha 2-adrenergic agonists. Anesthesiology 2000; 93 (5): 1345-1349.

4. Bi YH, Cui XG, Zhang RQ, Song CY, Zhang YZ. Low dose of dexmedetomidine as an adjuvant to bupivacaine in cesarean surgery provides better intraoperative somato-visceral sensory block characteristics and postoperative analgesia. Onco target 2017; 8 (38): 63587-63595.

5. Yousef AA, Salem HA, Moustafa MZ. Effect of mini-dose epidural dexmedetomidine in elective cesarean section using combined spinal-epidural anesthesia: a randomized double-blinded controlled study. J Anesth 2015; 29 (5): 708-714.

6. Sun Y, Xu Y, Wang GN. Comparative evaluation of intrathecal bupivacaine alone, bupivacaine-fentanyl, and bupivacaine-dexmedetomidine in Caesarean section. Drug Res (Stuttg) 2015; 65 (9): 468-472.

7. Bao Z, Zhou C, Wang X, Zhu Y. Intravenous dexmedetomidine during spinal anaesthesia for caesarean section: A meta-analysis of randomized trials. J Int Med Res 2017; 45 (3): 924-932.

8. Karaman S, Evren V, Firat V, Cankayali I. The effects of dexmedetomidine on spontaneous contractions of isolated gravid rat myometrium. Adv Ther 2006; 23 (2): 238-243.

9. Sia AT, Sng BL. Intravenous dexmedetomidine for obstetric anaesthesia and analgesia: converting a challenge into an opportunity? Int J Obstet Anesth 2009; 18 (3): 204-206.

10. Ala-Kokko TI, Pienimaki P, Lampela E, Hollmen AI, Pelkonen O, Vahakangas K. Transfer of clonidine and dexmedetomidine across the isolated perfused human placenta. Acta Anaesthesiol Scand 1997; 41 (2): 313-319.

11. Carbillon L, Uzan M, Uzan S. Pregnancy, vascular tone, and maternal hemodynamics: a crucial adaptation. Obstet Gynecol Surv 2000; 55 (9): 574-581.

12. Matoba T, Shimokawa $\mathbf{H}$. Hydrogen peroxide is an endotheliumderived hyperpolarizing factor in animals and humans. J Pharmacol Sci 2003; 92(1): 1-6.

13. Bagyánszki M, Novák Z, Bódi N, Orvos H, Pál A, Fekete E. Structural differences in the umbilical vein wall after full-term and pre-term delivery. Anat Histol Embryol 2009; 38 (5): 387-391.

14. Hamasaki J, Tsuneyoshi I, Katai R, Hidaka T, Boyle WA, Kanmura Y. Dual alpha(2)-adrenergic agonist and alpha(1)-adrenergic antagonist actions of dexmedetomidine on human isolated endothelium-denuded gastroepiploic arteries. Anesth Analg 2002; 94 (6): 1434-1440.

15. Yildiz O, Ulusoy HB, Seyrek M, Gul H, Yildirim V. Dexmedetomidine produces dual alpha (2)-adrenergic agonist and alpha (1)-adrenergic antagonist actions on human isolated internal mammary artery. J Cardiothorac Vasc Anesth 2007; 21 (5): 696-700. 
16. Lawrence CJ, Prinzen FW, de Lange S. Hemodynamic and coronary vascular effects of dexmedetomidine in the anesthetized goat. Acta Anaesthesiol Scand 1997; 41 (7): 830-836.

17. Coughlan MG, Lee JG, Bosnjak ZJ, Schmeling WT, Kampine JP, Warltier DC. Direct coronary and cerebral vascular responses to dexmedetomidine-Significance of endogenous nitric-oxide synthesis. Anesthesiology 1992; 77 (5): 998-1006.

18. Bodelsson G, Stjernquist M. Characterization of contractile adrenoceptors in the human umbilical artery. Eur J Pharmacol 1995; 282 (1-3): 95-101.

19. Talke P, Chen R, Thomas B, Aggarwall A, Gottlieb A, Thorborg P, Heard S, Cheung A, Son SL, Kallio A. The hemodynamic and adrenergic effects of perioperative dexmedetomidine infusion after vascular surgery. Anesth Analg 2000; 90 (4): 834-839.

20. Flacke JW, Flacke WE, Bloor BC, McIntee DF. Hemodynamic effects of dexmedetomidine, an alpha 2-adrenergic agonist, in autonomically denervated dogs. J Cardiovasc Pharmacol 1990; 16 (4): 616-623.

21. Akata T. General anesthetics and vascular smooth muscle: direct actions of general anesthetics on cellular mechanisms regulating vascular tone. Anesthesiology 2007; 106 (2): 365-391.

22. Kim JG, Sung HJ, Ok SH, Kwon SC, Cheon KS, Kim HJ, Chang KC, Shin IW, Lee HK, Chung YK, Sohn JT. Calcium sensitization involved in dexmedetomidine-induced contraction of isolated rata orta. Can J Physiol Pharmacol 2011; 89 (9): 681-689.

23. Posti JP, Valve L, Ruohonen S, Akkila J, Scheinin M, Snapir A. Dorsal hand vein responses to the $\alpha^{1}$-adrenoceptor agonist phenylephrine do not predict responses to the $\alpha^{1}$-adrenoceptor agonist dexmedetomidine. Eur J Pharmacol 2011; 653 (1-3): 70-74.

24. Wu D, Katz A, Lee CH, Simon MI. Activation of phospholipase C by alpha1-adrenergic receptors is mediated by the alpha subunits of $\mathrm{Gq}$ family. J Biol Chem 1992; 267 (36): 25798-25802.

25. Perez DM, DeYoung MB, Graham RM. Coupling of expressed alpha $1 \mathrm{~B}$ - and alpha1D-adrenergic receptor to multiple signaling pathways is both G protein and cell type specific. Mol Pharmacol 1993; 44 (4): 784-795.
26. Docherty JR. Subtypes of functional alpha1- and alpha2-adrenoceptors. Eur J Pharmacol 1998; 361 (1): 1-15.

27. Ward JP, Knock GA, Snetkov VA, Aaronson PI. Protein kinases in vascular smooth muscle tone-role in the pulmonary vasculature and hypoxic pulmonary vasoconstriction. Pharmacol Ther 2004; 104 (3): 207-231.

28. Minneman KP. Alpha 1-adrenergic receptor subtypes, inositol phosphates, and sources of cell Ca2+. Pharmacol Rev 1988; 40 (2): 87-119.

29. Parkinson NA, Hughes AD. The mechanism of action of alpha 2-adrenoceptors in human isolated subcutaneous resistance arteries. Br J Pharmacol 1995; 115 (8): 1463-1468.

30. Pihlavisto M, Scheinin M. Functional assessment of recombinant human alpha(2)-adrenoceptor subtypes with cytosensor microphysiometry. Eur J Pharmacol 1999; 385: 247-253.

31. Esmaoglu A, Ulgey A, Akin A, Boyaci A. Comparison between dexmedetomidine and midazolam for sedation of eclampsia patients in the intensive care unit. J Crit Care 2009; 24 (4): 551-555.

32. Toyama H, Wagatsuma T, Ejima Y, Matsubara M, Kurosawa S. Cesarean section and primary pulmonary hypertension: the role of intravenous dexmedetomidine. Int J Obstet Anesth 2009; 18 (3): 262-267.

33. Palanisamy A, Klickovich RJ, Ramsay M, Ouyang DW, Tsen LC. Intravenous dexmedetomidine as an adjunct for labor analgesia and cesarean delivery anesthesia in a parturient with a tethered spinal cord. Int J Obstet Anesth 2009; 18 (3): 258-261.

34. Sia A T, Kwek K, Yeo GS. The in vitro effects of clonidine and dexmedetomidine on human myometrium. Int J Obstet Anesth 2005; 14 (2): 104-107.

35. Gertler R, Brown HC, Mitchell DH, Silvius EN. Dexmedetomidine: a novel sedative-analgesic agent. Proc (Bayl Univ Med Cent) 2001; 14 (1): 13-21.

36. Kawano T, Yamazaki F, Chi H, Kawahito S, Eguchi S. Dexmedetomidine directly inhibits vascular ATP-sensitive potassium channels. Life Sci 2012; 90 (7-8): 272-277.

Received October 10, 2018. Accepted November 3, 2018. 